\title{
Hopes and fears and a national phobia
}

\section{Daniel S. Greenberg}

The Dread Disease: Cancer and Modern American Culture. By James T. Patterson. Harvard University Press: 1987. Pp.380. \$25.95, £20.75

IN 1970, the US Congress unanimously resolved that cancer should be cured by 1976 "as an appropriate commemoration of the two-hundreth anniversary of the independence of our country".

Hallucinogenic declarations are common on Capitol Hill. Little noticed, the decree stood among many posturing diversions from serious legislative business, a Democratic-inspired jab at Nixon's penny-pinching White House. But this was serious business. The subject was the most feared disease in the nation. The goal was the defeat of death, a universal favourite, but one especially cherished in yogurt-gulping, jogging American culture. Adoption of the resolution proved to be a major step towards passage of the National Cancer Act of 1971, which was quickly embraced by a previously opposed Nixon when it was bound to pass. (He attributed his interest to the death of an aunt by cancer.) Declaration of the "war on cancer" was followed by extraordinary sums of government research funds, some $\$ 15$ billion so far, making cancer the most richly financed field of research outside the blank-cheque realms of defence and space.

Good for cancer research - better there than in the aforementioned, many have said. But the abundance of money is difficult to justify in terms of the health needs of the American people. The death rate from cardiovascular diseases is double that from cancer, which remains predominantly a disease of the elderly. At the same time, the United States lags behind a dozen or so nations in controlling infant mortality. And some 37 million Americans lack insurance for health care, very little of which is given away in this land of free enterprise for the poor and subsidies for the rich.

Furthermore, the cancer establishment, until recently, has concentrated its wealth on a desperate quest for cures, while neglecting preventive measures. Backed by the US Treasury, the anything-goes, curative strategists have, for example, scooped up hundreds of thousands of samples of mud and plant matter from around the world in a futile search for nature's own cure for cancer. Meanwhile, the cancer warriors were late arrivals to the war on smoking.

How did cancer, among humanity's many afflictions, come to be so feared in the American psyche? And how did a self-perpetuating cancer establishment become so privileged, powerful and selective in the dispensation of immense

\section{biomedical resources?}

These questions are addressed by Professor Patterson, a historian at Brown University, in The Dread Disease. This is an ambitious and original attempt to advance past the bountiful literature on cancer politics produced in recent years by scholars, journalists and public-health activists. Patterson is only peripherally concerned with the biology and treatment of cancer and even less so with the clockwork of cancer legislation, for which Richard A. Rettig's Cancer Crusade: The Story of the National Cancer Act of cancer - a declaration of "war". Starting in the late nineteenth century, many elements started to come together, including growing expectations about the power of medicine and an uncritical press that relished tales of heroic scientific advance, and still does. (Patterson's collection of 'cure' reports from the serious wing of the American press illuminates a disgraceful chapter in journalism.)

But in the elevation of cancer into a national phobia, perhaps most important of all, Patterson states, was that "The denial of death was especially strong in the United States, land of perceived opportunity, technological progress, and economic growth" (p.32). Especially after the high-tech triumphs of the Second World War, Americans - now, for the first time, comfortable with government as problem solver - couldn't tolerate cancer.

In some of the most perceptive writing

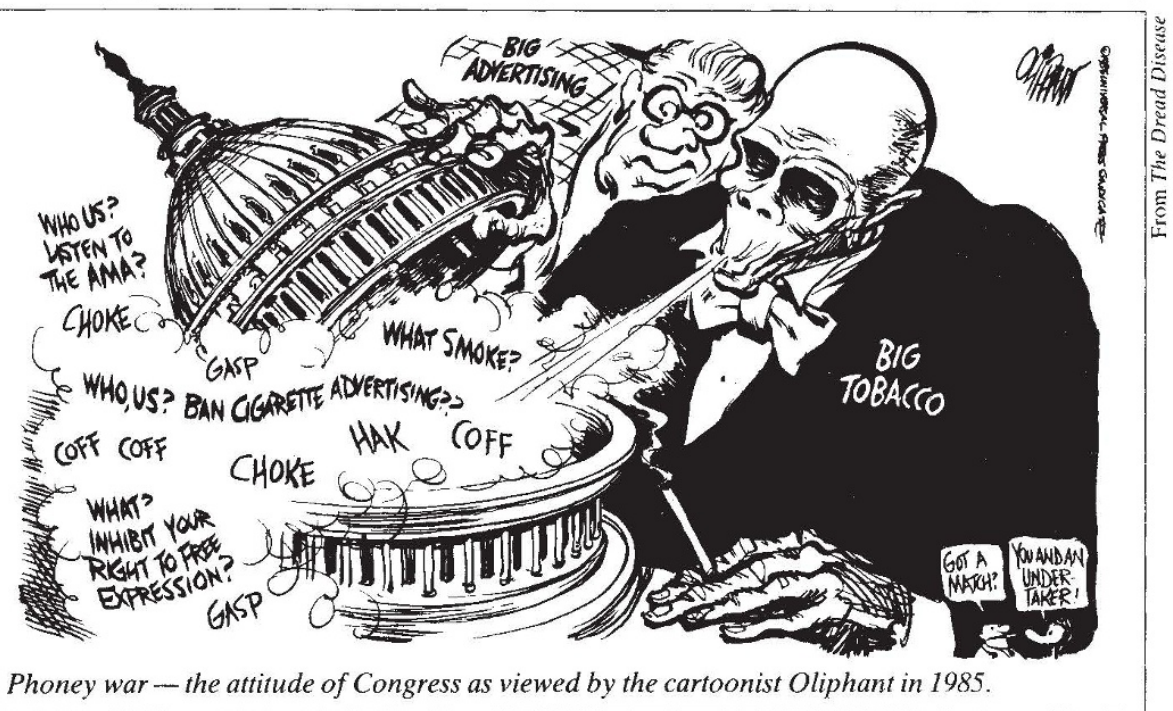

1971 (Princeton University Press, 1977), remains the standard work.

"Rather", Patterson explains,

I concentrate on elucidating the ways that the dread disease has reflected social and personal concerns during the modern, industrial era of United States history: concerns about illness, health, medical practices, and death and dying

.The history of cancer in America is also a history of social and cultural tensions

Many [Americans] clung defiantly to ideas about cancer that were scorned by the majority of scientists. Still others were simply terrified: the persistence and growth of popular cancerphobia are central themes of this book [pp. viii, ix].

Why cancer as the most feared disease, the darling of federal health research, the most popular object of medical charity, and the specific interest of very first institute to be founded in what eventually evolved into the great National Institutes of Health? The obvious part of the answer is that cancer has earned its horrifying reputation. But, as Patterson skilfully demonstrates, more than fear was needed to inspire America's unique reaction to yet produced on America's response to cancer, Patterson describes in detail the painful dichotomy between the victorious communiqués that routinely emanate from the cancer establishment and common personal experience with the disease. "In challenging the optimists", he concludes, "disillusioned Americans did not need to look very far for evidence".

Prevention is now the central theme of America's war on cancer, with the National Cancer Institute dedicated to halving the death rate by the year 2000 . Dietary modification and cessation of smoking are among the key elements in this strategy. Both, of course, could have been instituted as national policy 20 years ago. Why they weren't, and why the cancer-terrorized masses in the United States long tolerated the warped strategy against cancer, are well explained in this fine, important book.

Daniel S. Greenberg, 3736 Kanawha Street $N W$, Washington, DC 20015, USA, is editor and publisher of the newsletter Science \& Government Report, and a long-standing commentator on the "war on cancer". 